\section{Bleeding prophylaxis after polypectomy by colonoscopic application of a detachable snare with a mucosectomy cap}
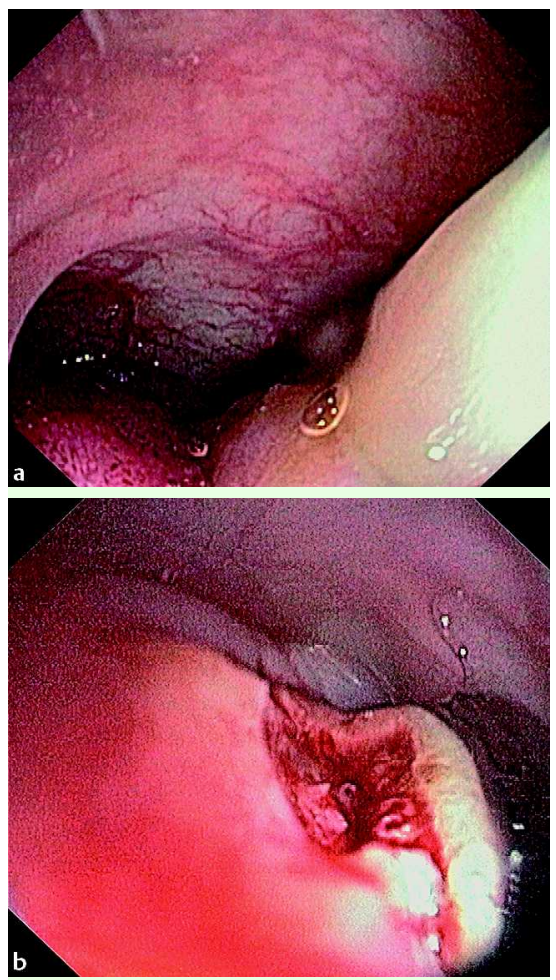

Fig. 1 a Large pedunculated polyp in the sigmoid colon. $\mathbf{b}$ Multiple vessels at the base of the polypectomy site.

A 4-cm pedunculated polyp ( $\odot$ Fig. 1 a) was discovered in the sigmoid colon of a 70-year-old patient who presented with anemia. Application of a detachable snare before removal of a polyp can prevent bleeding [1-3] but was not possible in this case because of the size of the polyp head and the softness of the snare. A polypectomy snare was successfully placed over the polyp head because this snare was stiffer. After injection of $6 \mathrm{ml}$ saline with epinephrine into the stalk, polypectomy was performed. After polypectomy, multiple vessels were seen at the base of the polypectomy site without bleeding (॰ Fig. 1 b).

Clips could not be used, because the base of the polypectomy site was not within the reach of the clip applicator. To prevent polypectomy-associated bleeding from the multiple visible vessels, we decided to place a detachable snare over the base of the polypectomy site. A detachable

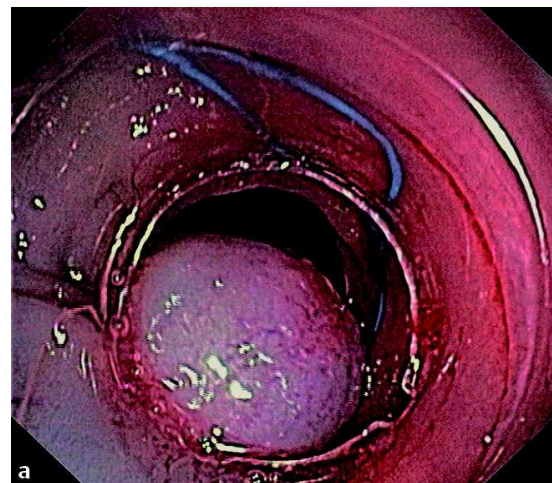

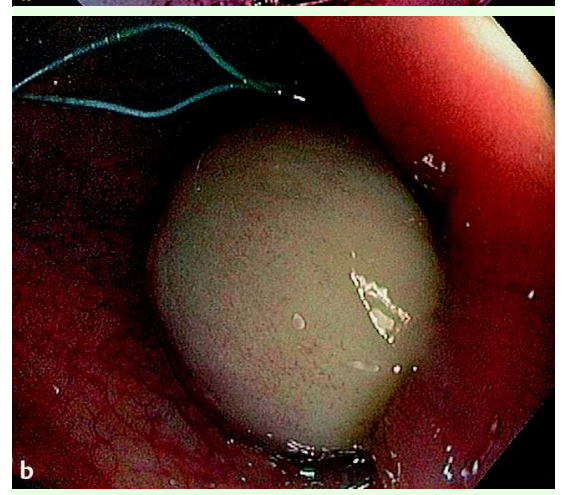

Fig. 2 a Application of the detachable snare using a mucosectomy cap after polypectomy. b The vessels together with the surrounding mucosa are completely strangulated.

snare (Olympus MAJ-340) was placed in a transparent mucosectomy cap (Olympus MAJ-293) as in the endoscopic mucosectomy technique ( $\bullet$ Fig. 2 a). Once the base of the polypectomy site had been sucked into the cap, under direct endoscopic view, the snare was delivered and the vessels together with the surrounding mucosa completely strangulated (॰ Fig. 2 b).

No complication occurred. Histological evaluation revealed a completely resected tubular adenoma with low-grade intraepithelial neoplasia.

The combination of a detachable snare used with a transparent mucosectomy cap may provide another way to prevent postpolypectomy bleeding in the colon.
M. Zachäus, U. Künzel, U. Halm

Parkkrankenhaus Leipzig-Südost $\mathrm{GmbH}$, Department of Internal Medicine II, Leipzig, Germany

\section{References}

1 Iishi $H$, Tatsuta M, Narahara $H$ et al. Endoscopic resection of large pedunculated polyps using a detachable snare. Gastrointest Endosc 1996; 44: 594- 597

2 Di Giorgio P, De Luca L, Calcagno G et al. Detachable snare versus epinephrine injection in the prevention of postpolypectomy bleeding: a randomized and controlled study. Endoscopy 2004; 36: 860-863

3 Paspatis GA, Paraskeva K, Theodoropoulou A et al. A prospective, randomized comparison of adrenaline injection in combination with detachable snare versus adrenaline injection alone in the prevention of postpolypectomy bleeding in large colonic polyps. Am J Gastroenterol 2006; 101: 2805 - 2809

Bibliography

DOI $10.1055 / \mathrm{s}-2007-995692$

Endoscopy 2008; 40: E159

(c) Georg Thieme Verlag KG Stuttgart · New York . ISSN 0013-726X

Corresponding author

\section{Zachäus, MD}

Department of Internal Medicine II

Strümpellstraße 41

04289 Leipzig

Germany

Fax: +49-341-8642264

markuszachaeus@aol.com

markus.zachaeus@parkkrankenhaus-leipzig.de 